\title{
New developments in the assessment of COPD: early diagnosis is key
}

This article was published in the following Dove Press journal:

International Journal of COPD

27 February 2014

Number of times this article has been viewed

\author{
Nicholas G Csikesz \\ Eric J Gartman \\ Warren Alpert Medical School \\ of Brown University, Division of \\ Pulmonary, Critical Care, and Sleep \\ Medicine, Memorial Hospital of \\ Rhode Island, Pawtucket, RI, USA
}

Correspondence: Eric J Gartman Warren Alpert Medical School of Brown University, Division of Pulmonary, Critical Care, and Sleep Medicine, Memorial Hospital of Rhode Island, I I I Brewster Street, Pawtucket, RI 02860, USA

$\mathrm{Tel}+\mathrm{I} 4017292636$

Fax +l 40I 7292157

Email eric_gartman@brown.edu
Abstract: Chronic obstructive pulmonary disease (COPD) is the most common chronic lung disease in the world, and its associated health burdens and costs are mounting. Until recently, it was generally accepted that targeting the diagnosis of COPD early in its course was a relatively fruitless effort, since treatments other than already ubiquitous smoking-cessation efforts were unlikely to alter its course. However, there is strong evidence to suggest that the majority of patients with objective COPD are not aware of their condition, and this leads to a significant delay in diagnosis, more aggressive smoking-cessation intervention, and potential treatment. Novel methods of diagnostic testing, community health programs, and primary-care provider recommendations hold promise to expand the recognition of COPD in its incipient stages - where recent evidence suggests a rapid decline in lung function occurs and may be prevented if acted upon. This review explores the evidence to support the efforts to justify programs aimed at early diagnosis, alternative diagnostic strategies that may augment traditional spirometry, therapeutic modalities that could potentially be used in the future to alter early lung-function decline, and emphasizes the necessary cooperative role that physicians, patients, communities, and governments need to play to realize the significant health impact that stands to be gained.

Keywords: early diagnosis, spirometry, smoking cessation, lung function

\section{Introduction}

Chronic obstructive pulmonary disease (COPD) is the most common chronic lung disease in the world and is a major cause of morbidity and mortality worldwide. ${ }^{1}$ Exposure to tobacco smoke or other air pollutants in susceptible individuals leads to inflammation in the small airways and progressive destruction of lung parenchyma, resulting in a decline in lung function out of proportion to the normal decline seen with aging. The manifestations of this disease are heterogeneous, resulting in a wide range of clinical phenotypes, as reflected in the recent update to the Global initiative for chronic Obstructive Lung Disease (GOLD) criteria, which acknowledges a significant dichotomy within the COPD population with regard to the relative frequency of acute exacerbations of disease. ${ }^{1}$

Traditional opinion has described COPD as a progressive disease that responds poorly to treatment, with the lone intervention capable of altering the course of disease progression being smoking cessation..$^{2-5}$ However, recent studies have called these axioms into question. The period of most rapid decline in lung function may occur much earlier than previously thought, and it is during this period that aggressive testing strategies, smoking-cessation efforts, and the initiation of treatments may be beneficial. ${ }^{6,7}$ In reflection of this, modification of our current diagnostic approaches 
and adoption of alternative modalities may allow for earlier identification of patients with disease. ${ }^{8-14}$ This early recognition also may allow practitioners to appropriately recognize exacerbations of a chronic lung disease, whereas without this defined diagnosis, they may initially be labeled as having multiple bouts of acute disease (eg, bronchitis). Further, pharmacologic therapy initiated early in the course of COPD (in addition to smoking cessation) may alter the rate of disease progression. ${ }^{4,15-17}$ For these reasons, establishing and acting on an early diagnosis of COPD is a critical step in reducing the extensive morbidity and mortality of this disease.

\section{Epidemiology}

As mentioned, COPD is the most common chronic lung disease in the world - with an estimated pooled prevalence of $7.6 \%-8.9 \%{ }^{18}$ It has been several generations since the impact of cigarette smoking on chronic lung disease was first recognized, yet worldwide rates of smoking have not been universally declining. For example, while smoking rates in the USA and Canada have decreased significantly over the past 50 years, rates in many nations in Asia and Africa remain extremely high. ${ }^{18-20}$ Additionally, perhaps because of the long lead time required to develop clinically significant COPD, even in areas where smoking rates have fallen, there has yet to be as significant a decline in COPD. ${ }^{21}$ As a result, a commensurate decline in the prevalence of COPD should be expected in certain areas, but a rise in others. ${ }^{22}$

To illustrate this effect, several large survey-based studies analyzed changes in the prevalence of obstructive lung function (and, specifically, COPD) in the USA over the past 20 years. ${ }^{23,24}$ Ford et al compared the data from the National Health and Nutrition Examination Surveys for adults aged 20-79 from the periods 1988-1994 and 2007-2010. ${ }^{24}$ They found that the overall age-adjusted prevalence of any obstructive lung disease was $13.5 \%$ in 2007-2010, compared with $14.6 \%$ in $1988-1994$ ( $P=0.178)$. Of concern, a high percentage of participants with moderate $(48.4 \%)$ and severe $(37.9 \%)$ obstructive lung function reported that they were continuing to smoke. The same group incorporated multiple datasets to address the burden of COPD over the period from 1999 to $2011 .^{23}$ They found a self-reported incidence of COPD of $6.5 \%$ in 2011, which was illustrative of a small linear decrease in prevalence over the study period. Rates were higher in women (which has been found in other studies in which prevalence of COPD is self-reported, as opposed to studies based on objective data, which typically show higher prevalence in men). ${ }^{25}$ There was also significant geographic variation, with higher prevalence of COPD, COPD hospitalizations, and COPD mortality in the Southern states and along the Ohio River Valley, which was similar between 1999 and 2011. An additional study reflecting the population of Great Britain further illustrates both the overall burden of COPD and the evident disconnect between objective disease presence and self-perception. Shahab et al reported a prevalence of spirometry-diagnosed COPD of $13.3 \%$, with $80 \%$ of those participants denying any respiratory diagnosis. ${ }^{26}$ In sum, these population-based data confirm that despite some promising trends in rates of cigarette smoking and in the prevalence of lung disease, COPD is a significant public-health burden that largely goes unrecognized by those it affects.

Until recently, much of the available information regarding COPD prevalence was focused on the developed world; however, many areas of the developing world (eg, China, India) have very high rates of smoking as well as non-tobacco-associated COPD. In 2007, Zhong et al examined the prevalence of COPD in China using a spirometry-based cross-sectional survey. ${ }^{27}$ They found an overall prevalence of $8.2 \%$. Importantly, only $35 \%$ of the survey participants who had spirometric evidence of COPD had been previously diagnosed. Additionally, the prevalence of COPD was higher in rural residents and in those with less education and who had poor ventilation in the kitchen, suggesting that patients of low socioeconomic status are at increased risk. This finding was corroborated in a study by Yin et al in 2011. ${ }^{28}$ Using self-reported physician diagnosis as a means of assessing COPD status, they found that low socioeconomic status conferred a significantly increased risk of COPD diagnosis, even when controlled for age, sex, and smoking status. These patients also may be disadvantaged once diagnosed, as patients with disease in these areas may not have access to what are considered, in the Western world, standard pharmacologic therapies. ${ }^{27,29}$

As much as one-quarter of all COPD may be in patients with non-smoking-related disease. ${ }^{30} \mathrm{~A}$ recent meta-analysis by $\mathrm{Hu}$ et al confirmed that biomass smoke exposure is independently associated with an increased risk of COPD. ${ }^{31}$ There also appears to be an additive effect when combined with tobacco use. While this is generally considered a problem of the developing world, a study by Sood et al showed that $26 \%$ of a cohort of smokers in the American Southwest reported woodsmoke exposure, and that those with exposure had higher rates of COPD. ${ }^{32}$ While smokingcessation campaigns remain of paramount importance, reducing biomass smoke exposure should be considered equally important. 


\section{Course of illness}

The initial work of Fletcher and Peto suggested that the rate of decline in lung function in COPD patients accelerated as the disease progressed over time (Figure 1). ${ }^{5}$ However, more recent research suggests that the most rapid decline in lung function may occur much earlier in the disease course. ${ }^{6,7}$ Tantucci et al reviewed the spirometric data of COPD patients in the placebo arms of recent clinical trials and found that the mean rate of forced expiratory volume in 1 second $\left(\mathrm{FEV}_{1}\right)$ decline was greatest in GOLD Stages II and III COPD and slowed down in more advanced disease (Figure 2). ${ }^{6}$ Drummond et al reviewed data from the Lung Health Study, which was a longitudinal study of smokers with mild-to-moderate airflow obstruction randomized to intensive smoking cessation with or without bronchodilator therapy. ${ }^{7}$ Similarly, they found a rapid rate of decline in lung function in patients with only moderate disease. ${ }^{7}$ These data are consistent with the hypothesis that the rate of decline in lung function may follow the sigmoid curve pattern seen so commonly in nature, which would suggest an opportunity to prevent significant morbidity if COPD could be diagnosed and arrested prior to the period of most rapid decline in $\mathrm{FEV}_{1}$.

In attempts to augment the ability to elucidate those at risk for lung-function decline, radiographic measures have also been used to predict disease course. Nishimura et al conducted an observational cohort study of patients with COPD in which they performed regular spirometry and chest computed tomography (CT) over a 5 -year period. ${ }^{33}$ They found that emphysema severity, as evaluated by $\mathrm{CT}$, was independently associated with a rapid decline in $\mathrm{FEV}_{1}$; whereas \% predicted $\mathrm{FEV}_{1}$ was not, suggesting that this may be an alternative means of predicting which COPD patients are more likely

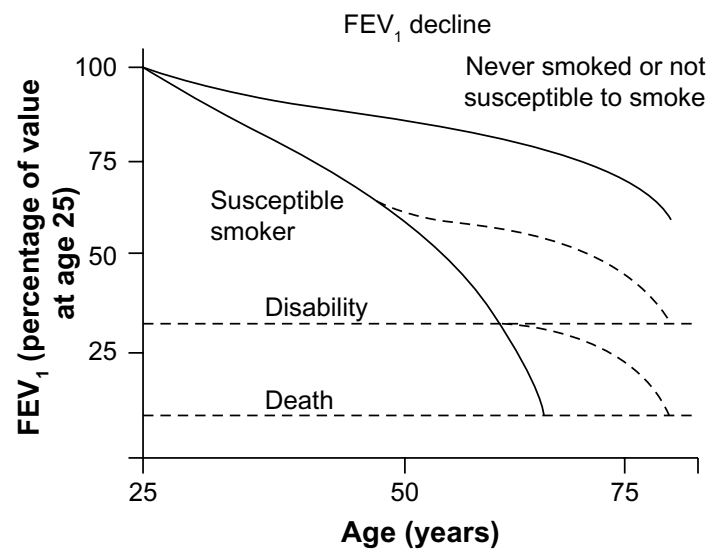

Figure I Conventionally accepted time course of the natural progression of lung function as a result of exposure to smoking.

Note: Reproduced from The natural history of chronic airflow obstruction. Fletcher C, Peto R. Br Med J. I(6077):1645-1648. Copyright (c) 1977 with permission from BMJ Publishing Group Ltd. ${ }^{5}$

Abbreviation: $\mathrm{FEV}_{1}$, forced expiratory volume in I second.

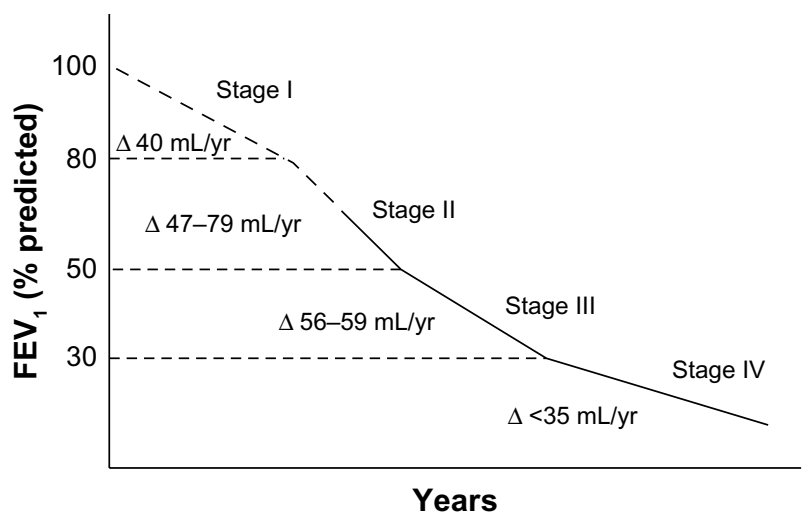

Figure 2 Recent evaluation of rate of decline in lung function in patients with chronic obstructive pulmonary disease demonstrating that the largest rate of decline in lung function may occur in moderate disease.

Notes: Copyright (C) 2012. Dove Medical Press. Reproduced from Lung function decline in COPD. Tantucci C, Modina D. Volume 7:95-99. ${ }^{6}$

Abbreviation: FEVI, forced expiratory volume in I second.

to progress rapidly. Similarly, emphysema distribution has been studied in this manner: Tanabe et al followed 131 male patients with COPD for a period of nearly 4 years ${ }^{34}$ while Mohamed Hoesein et al followed 587 male COPD patients for 3 years. ${ }^{35}$ Both groups found that a greater extent of lower-lobe CT-quantified emphysema was associated with a more rapid decline in lung function compared with those patients whose emphysema was limited to upper lobe disease.

\section{Disease heterogeneity}

It is well established that COPD is a heterogeneous disease, and often the presence of symptoms and functional limitation do not match the level of objective lung-function loss. In reflection of this, the most recent guidelines released by the GOLD divide patients into four main categories stratified by spirometry, symptoms, and frequency of exacerbations. ${ }^{1}$ Several large studies have been constructed to attempt to better identify distinct subpopulations within this wide spectrum of illness. The Evaluation of COPD Longitudinally to Identify Predictive Surrogate Endpoints (ECLIPSE) trial is an observational study conducted in Europe that enrolled 2,164 patients with clinically stable COPD, 337 smokers with normal lung function, and 245 never smokers. ${ }^{36}$ Study investigators measured clinical parameters, spirometry, exercise tolerance, and amount of emphysema by CT over 3 years of follow-up. Initial results showed that while severity of airflow limitation as assessed by spirometry correlated well with CT findings of emphysema, neither measure correlated particularly well with patient-reported symptoms, number of exacerbations, or objective measurements of exercise capacity.

The Subpopulations and Intermediate Outcomes in COPD Study (SPIROMICS) is a multicenter prospective 
cohort study that plans to enroll 3,200 patients in four groups (nonsmokers, smokers with normal lung function, mild/moderate COPD, and severe COPD). ${ }^{37}$ These patients will be followed for 3 years and data collected will include clinical status, spirometry, exercise capacity (6-minute walk test), blood and urine specimens, CT scans, and a series of questionnaires.

The Genetic Epidemiology of COPD (COPDGene) study will enroll 10,000 smokers with and without COPD. ${ }^{38}$ These patients will be followed longitudinally, and data collected will include clinical, radiographic, and spirometric measures. Additionally, a genome-wide association study will be done on a subset of study participants, which will address important questions about the genetic factors underlying the diverse manifestations of COPD.

Together, these three studies should provide a wealth of data that should greatly increase our overall understanding of COPD - with the hope we may find opportunities to meaningfully alter the progressive course of this disease.

\section{Diagnosis}

\section{Traditional spirometry}

The GOLD has defined COPD, based on spirometry, as an

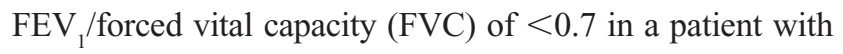
symptoms of dyspnea and/or chronic cough/sputum production, with an exposure history to cigarette smoke or other known toxins (ie, biofuels, occupational dusts, etc). ${ }^{1}$ This cutoff was deliberately chosen to make it as straightforward as possible to use in clinical practice. In recent years, there has been some controversy as to whether the fixed cutoff of 0.7 is appropriate or whether a more dynamic cutoff that better accounts for age, sex, and other factors should be entertained.

The $\mathrm{FEV}_{1}$ is known to decrease slightly out of proportion to the FVC with aging, such that using a cutoff of 0.7 may underdiagnose younger patients and overdiagnose older patients. ${ }^{39}$ It has been proposed that a more dynamic definition be employed to mitigate this problem, with the "lower limit of normal" (LLN) cutoff being defined as the bottom $5 \%$ of the population. ${ }^{40}$ Regardless of the cutoff used, spirometry needs to be interpreted in clinical context. Mohamed Hoesein et al performed an evidence-based review of this question. ${ }^{41}$ They found that using a fixed cutoff of 0.7 diagnosed more patients with COPD based on more diagnoses in older patients, as could be expected. Importantly, the group of patients with an $\mathrm{FEV}_{1} / \mathrm{FVC}$ of $<0.7$ but greater than the LLN had higher mortality and more hospitalizations than patients with normal lung function, suggesting that LLN may underestimate COPD. Bhatt et al reported similar findings in a recent analysis of data from the COPDGene study. ${ }^{42}$
The discussion on the optimal interpretation strategy for spirometry is ongoing. Of greater importance is that, regardless of which cutoff is used, clinicians must have the diagnosis in mind, and order spirometry for at-risk patients, interpreting the results in the context of each patient.

\section{Impulse oscillometry/specific airway conductance}

While spirometry is the most commonly used pulmonary function test in diagnosing and following COPD, it may not be the most sensitive test, and may have particular limitations in identifying early disease. Borrill et al have studied impulse oscillometry and specific airway conductance in comparison to $\mathrm{FEV}_{1}$ in patients with COPD exposed to subtherapeutic doses of short- and long-acting bronchodilators. ${ }^{8,9}$ They found that both measures were able to identify more subtle changes in lung function than traditional spirometry. Similarly, several studies have shown that impulse oscillometry measurements can identify abnormalities in patients who report symptoms of COPD but do not yet have abnormal spirometry. ${ }^{10,11}$ As such, these complementary diagnostic modalities, while likely to not ever replace spirometry, could potentially aid in the early recognition of COPD - especially in those whose symptoms are disproportionate to their spirometry.

\section{Role of radiology}

While pulmonary function tests remain the standard diagnostic tool for COPD, the ability of radiographic studies to identify emphysema has made imaging a focus of recent interest in diagnosing or categorizing COPD. Mets et al looked at the value of three different parameters calculated with an automated algorithm on CT scans done for the purposes of lung-cancer screening. ${ }^{12}$ They compared the diagnostic value of emphysema, air trapping, and bronchial wall thickening to pre-bronchodilator spirometry in 1,140 male lung-cancer screening participants using low-dose CT with inspiratory and expiratory sequences. Using a pre-bronchodilator $\mathrm{FEV}_{1} /$ FVC of $<0.7$ as the standard for COPD, a diagnostic model incorporating all three of these findings had a sensitivity of $73.2 \%$ and specificity of $88.8 \%$. The study being discussed evaluated three different parameters from CT scan for diagnosis of COPD. One of these three, air trapping, required additional expiratory images to be obtained. Excluding this parameter (and thus the additional radiation necessary to acquire it) still provided a reasonably high sensitivity and specificity for diagnosis of COPD. Owrangi et al used high-resolution CT to compare ex-smokers with and without COPD and created an automated measure using density histogram analysis that identified spirometry-defined COPD 
with a $91 \%$ classification rate. ${ }^{13}$ In sum, the important message from these studies is that parenchymal changes associated with COPD are evident on CT, and, if evident from the incipient stages of disease, may hold promise for aiding in the early detection of COPD prior to the overwhelming loss in lung function.

CT has also been studied as a means of prognosticating mortality in patients with COPD. Johannessen et al used mortality data from the Norwegian Cause of Death Registry in patients from the Norwegian GenKOLS study, which took 947 ever-smokers aged 40-85 and performed spirometry and CT. ${ }^{14}$ They found that the percentage of low-attenuation areas on CT scan was a strong independent predictor of mortality, which was further influenced by assessment of airway wall thickness. The predictive power of percentage of low-attenuation areas was seen irrespective of the presence or stage of COPD.

In a study evaluating the utility of ventilation/perfusion single-photon emission tomography (V/P SPECT) in COPD, Jögi et al compared ventilation/perfusion single-photon emission tomography, emphysema extent assessed by high-resolution CT, and spirometry with clinical status using the Medical Research Council dyspnea questionnaire and the clinical COPD questionnaire. While ventilation/perfusion single-photon emission tomography correlated well with emphysema extent and spirometric lung function, none of the objective tools correlated well with patients' clinical parameters as determined by the survey results. ${ }^{43}$ This study highlights two important ongoing themes in the diagnosis and classification of COPD: 1) the symptoms and patient perception of disease are not good early markers of lung destruction or functional decline, and 2) regardless of the diagnostic tool that is used, given the enormous crossover between respiratory symptoms and objective disease presence, clinical correlation remains of paramount importance.

\section{Biomarkers}

The National Cancer Institute defines a "biomarker" as "a biological molecule found in blood, other body fluids, or tissues that is a sign of a normal or abnormal process, or of a condition or disease". ${ }^{44}$ Currently, there are no such molecules in routine clinical use in the diagnosis or management of COPD; however, efforts are being made to identify useful measurements that may expedite the identification of those at risk for progressive chronic lung disease.

\section{Serum markers}

Based on prior work suggesting that adiponectin may play a role in the pathogenesis of emphysema, Carolan et al studied patients with and without COPD from the
COPDGene study. ${ }^{45}$ They found that higher plasma adiponectin levels were independently associated with CT-measured lower-lobe emphysema, which has been shown to correlate with more rapid decline in lung function, as mentioned previously in this review. Cheng et al utilized data from the ECLIPSE cohort as well as a separate study cohort to look at the soluble receptor for advanced glycation end products (RAGE). ${ }^{46}$ They found that lower levels of soluble RAGE correlated strongly with the severity of emphysema in both cohorts. Additionally, they identified several singlenucleotide polymorphisms in the gene coding for RAGE that correlated with RAGE levels.

Wang et al used metabonomic profiling of serum and urine by $\mathrm{H}$-nuclear magnetic resonance-based spectroscopy to show that they could discriminate between patients with COPD and healthy controls based on metabolic differences in serum, and especially urine. ${ }^{47}$ Meanwhile, Thomashow et al studied the presence of endothelial microparticles in patients with mild COPD and emphysema. ${ }^{48}$ They found that endothelial microparticles were elevated in COPD compared with in controls, even in mild COPD, and were well correlated to percent emphysema (assessed by CT scan), pulmonary microvascular blood flow, and diffusing capacity.

\section{Exhaled biomarkers}

Measuring biomarkers in exhaled gas is an appealing diagnostic test both theoretically, for a disease of the airways, and practically, for a patient population familiar with having regular testing of their breathing function. ${ }^{49}$ The fraction of exhaled nitric oxide (NO) is an established biomarker in asthma; however, data supporting its use in COPD are not as robust. ${ }^{50} \mathrm{~A}$ recent study by Brindicci et al found that measuring exhaled NO at different flows could partition it into alveolar and bronchial components. ${ }^{51}$ Consistent with the fact that COPD is a disease of the alveoli and small airways, the alveolar component of exhaled NO correlated strongly with COPD severity, an association that persisted even after controlling for smoking status, time of day, and use of inhaled bronchodilators or corticosteroids. Similar to measuring exhaled gas concentrations, exhaled breath condensate has been used to identify markers in COPD as well. ${ }^{52}$

\section{Conclusion}

While all these studies are promising, there is still no reliable biomarker that can be recommended for routine clinical use. Additional results from the COPDGene, ECLIPSE, and SPIROMICS cohorts, among other studies, should continue 
to add to this field in coming years, and further our ability to identify earlier those patients at highest risk.

\section{Treatment Impact of smoking cessation}

Smoking cessation is of ultimate importance in arresting the process of lung-function decline in COPD, and should be the emphasis of any program that aims to intervene in COPD at an early stage. The Lung Health Study followed smokers with mild obstruction who were randomized to intensive smoking cessation with or without an inhaled bronchodilator compared with smokers in whom no intervention was used. ${ }^{2}$ They found that patients who ceased smoking had a markedly reduced decline in $\mathrm{FEV}_{1}$ over a 5-year period compared with those who did not. In contrast, treatment with a bronchodilator did not significantly affect the decline in lung function over time. Similarly, multiple large trials from the 1990s and 2000s failed to show any disease-modifying effect from medical therapy (EUROSCOP, Copenhagen Heart, ISOLDE, BRONCUS). ${ }^{4}$ Further, data from the Seven Countries Study show that there is a mortality benefit to smoking cessation, regardless of severity of lung disease. ${ }^{53}$ This benefit is most likely driven by a reduction in cardiovascular mortality rather than an effect on respiratory-related mortality; however, the benefit to the patient remains the same.

\section{Biomass}

Just as smoking cessation is of paramount importance in smoking-related COPD, decreasing or eliminating exposures in non-smoking-related COPD must also be a focus. A retrospective analysis by Chapman et al showed that the installation of chimneys in houses with previously unvented stoves resulted in a significant reduction in the incidence of COPD in both men and women. ${ }^{54}$ However, measurements of carbon monoxide and particulate matter in a subset of Chinese homes participating in China's National Improved Stove Program found levels that were still higher than national standards. ${ }^{55}$ Further interventions to reduce exposure in this population may represent "low-hanging fruit" in combating the global COPD epidemic, and merit further resources and attention.

\section{Early treatment}

In contrast to these findings, several more recent studies have suggested that compliance with prescribed bronchodilator therapy may actually have some benefits in limiting the decline in $\mathrm{FEV}_{1}$.
The Understanding Potential Long-term Impacts on Function with Tiotropium (UPLIFT) study was a multicenter, randomized, placebo-controlled trial of the effects of tiotropium on patients with COPD over a 4-year study period. Patients receiving tiotropium had an early improvement in $\mathrm{FEV}_{1}$ that was maintained throughout the study period, in addition to fewer exacerbations and improved scores on the St George's Respiratory Questionnaire. ${ }^{15}$ In a subset of patients with GOLD Stage II disease who had multiple follow-up measurements of spirometry, those receiving tiotropium had a small but significant decrease in the rate of decline in postbronchodilator $\mathrm{FEV}_{1}$ compared with those receiving a placebo $\left(\mathrm{FEV}_{1}\right.$ decline $43 \mathrm{~mL} /$ year vs $49 \mathrm{~mL} /$ year, $\left.P=0.024\right) .{ }^{15} \mathrm{It}$ should be stated that this was not seen for pre-bronchodilator measurements, and the absolute change is not one generally thought to be of functional significance - although it could be representative of a more general modification of disease activity/progression, as evidenced by the other measured outcomes (eg, exacerbation rates and symptoms).

Several additional studies looked at the effect of inhaled therapies on rates of lung-function decline and other outcomes in patients with less severe disease. The Towards a Revolution in COPD Health (TORCH) study was a doubleblind placebo-controlled trial of the effect of inhaled salmeterol and fluticasone, either alone or in combination, in patients with moderate/severe COPD (pre-bronchodilator $\mathrm{FEV}_{1}$ of $<60 \%$ ). A post hoc analysis showed that all three treatment arms showed mild reductions in the rate of decline of $\mathrm{FEV}_{1}$ in patients with moderate and severe (but not very severe) COPD. ${ }^{3,4,15,16}$ Cukic et al compared changes in pulmonary function over a 4-year period based on therapeutic compliance. Patients regularly receiving bronchodilator therapy had less decline in $\mathrm{FEV}_{1}$ than those who were not over the study period. ${ }^{17}$ The Spiriva Usual Care (SPRUCE) study was a placebo-controlled trial of tiotropium in nearly 400 patients with a mean $\mathrm{FEV}_{1}$ of $49 \%$ predicted. ${ }^{56}$ In the subset of patients with mild/moderate disease $\left(\mathrm{FEV}_{1}>50 \%\right.$ predicted $)$, there were fewer exacerbations and mild improvement in lung function at the conclusion of the 12-week study period. The Mesure de 1'Influence de Spiriva ${ }^{\circledR}$ sur les Troubles Respiratoires Aigus à Long terme (MISTRAL) study was also a placebo-controlled trial of tiotropium in patients with a mean $\mathrm{FEV}_{1}$ of $48 \%$ predicted. ${ }^{57}$ Similar to the SPRUCE trial, patients treated with tiotropium had fewer exacerbations than those treated with placebo, but also demonstrated reduced health care utilization (as measured by unscheduled doctor visits and the number of prescriptions for oral antibiotics or steroids). A trial of tiotropium's effect on exercise limitation 
and breathing capacity in early COPD has been recently completed, without published results to date..$^{58}$

While it should be emphasized again that the primary message in early intervention for COPD should be advocacy of smoking cessation, these data are suggestive that there may be interventions that could slow the progression of disease in those patients who choose to continue to smoke and/or already have documented COPD. Based on the evidence outlined here, newer therapies may warrant implementation for their disease-modifying effects, in addition to any effects they have in terms of preventing exacerbations and improving quality of life.

\section{Alternative treatment regimens}

Current guidelines recommend inhaled bronchodilators with/ without inhaled corticosteroids as the mainstay of treatment in COPD. ${ }^{1}$ Recent research studies looking at alternative means of therapy exist, and these therapies include new uses for old therapies, as well as novel agents aimed at newly identified targets in the COPD disease pathway.

\section{Old therapy, new use}

$\mathrm{N}$-acetylcysteine is an older drug known to have both mucolytic effects and anti-inflammatory/antioxidant properties. It has been studied in the treatment of pulmonary fibrosis, prevention of contrast-induced nephropathy, and COPD overall, with variably observed clinical benefit. A recent trial of high-dose $\mathrm{N}$-acetylcysteine in patients with stable COPD (mean $\mathrm{FEV}_{1}$ 53.9\% predicted) showed significant improvements in the spirometric measurements of smallairway function and fewer exacerbations at 1 year without significant adverse effects. ${ }^{59}$

Theophylline has been used for many years in the treatment of airway disease. ${ }^{60}$ It has generally fallen out of favor due to a narrow therapeutic window and less efficacy than inhaled bronchodilators. However, recent studies have identified a potent anti-inflammatory effect at lower doses that suggests the drug may be useful as a steroidsparing therapy in patients with severe COPD. ${ }^{60}$ Several clinical trials addressing this possibility are in varying stages of completion. ${ }^{61-63}$

\section{New therapy}

COPD is a disease of chronic inflammation and lung destruction, so it is therefore not surprising that treatment with bronchodilator medications alone would have mixed effects on mitigating disease progression. Multiple sites in the inflammatory pathway have been identified as potential therapeutic targets. These include interleukins (ILs; ie, IL-1, IL-6, IL-8, IL-17, IL-18), tumor-necrosis factor, and transforming growth factor beta ${ }^{64}$ Allogeneic mesenchymal stem cells have also been studied to assess their effects on the inflammatory and reparative process. ${ }^{65}$ While investigations addressing these targets have by no means been exhaustive, the studies that have been performed have failed to show significant benefit to date. This likely is another example of the current impasse that medical knowledge has reached in a variety of conditions. In many instances, while the pathways and targets have been well elucidated, it has proven remarkably challenging to affect these pathways in a meaningful way, as they are full of duplications/parallel pathways such that suppressing one given target may have minimal or no effect on the overall signal produced by a pathway.

\section{Pulmonary rehabilitation}

The benefit of pulmonary rehabilitation in patients with moderate-to-severe COPD is now widely accepted, and has become an important component of therapy in patients with advanced disease. ${ }^{66,67}$ Patients with recent hospitalizations for acute exacerbations have been recognized as a population for whom rehabilitation may be particularly effective. ${ }^{68}$ Providing patients with convenient access to a rehabilitation facility has been a barrier to widespread implementation. A recent review of home-based pulmonary rehabilitation programs suggests that these may be an alternative option for some patients, allowing for greater overall implementation. ${ }^{69}$ While rehabilitation has traditionally been reserved for patients late in their disease course, even patients with early disease are less physically active than those without disease. ${ }^{70}$ A recent systematic review of the available data for pulmonary rehabilitation in patients with mild COPD showed evidence of improved exercise capacity and health-related quality of life. ${ }^{71}$ Further studies are necessary to confirm these findings, but counseling patients to increase physical activity should likely be included in discussing management in patients with newly diagnosed disease.

\section{Feasibility of early diagnosis Importance of primary care}

Achieving the goal of early diagnosis in COPD may prove to be a significant challenge. As has been seen in the recent studies regarding screening $\mathrm{CT}$ scans for lung cancer, screening a wide population of at-risk patients can result in earlier diagnosis, but presents significant direct health care costs as well as the issues of frequent false-positives. ${ }^{72}$ Dirven et al published two studies addressing the fundamental question of 
how to practically implement a screening model to diagnose COPD early. ${ }^{73,74}$ They addressed two different facets of this question, looking at the feasibility and cost-effectiveness of implementing a screening model in primary-care practices in areas of different socioeconomic status, and also looked at whether a patient-driven or provider-driven approach achieved more diagnoses of COPD. They found that asking a primary-care practice to initiate a respiratory healthscreening questionnaire and ordering spirometry based on the results was feasible, effective, and acceptable to the providers involved. While both a patient-driven and provider-driven questionnaire tool diagnosed cases of COPD, more cases were identified in the provider-driven model, regardless of the socioeconomic status of the practice being studied.

\section{Alternative paths to diagnosis}

The role of the primary-care provider in identifying at-risk patients and directing them toward diagnosis is critical. This is not the only opportunity for identifying these patients, however. In a compelling pilot study in Barcelona, Castillo et al instructed pharmacists to identify at-risk patients ( $>40$ years-old with respiratory symptoms and/or smoking history) and screened them with a simple five-item screening questionnaire. ${ }^{75}$ Patients identified by this method were then offered in-pharmacy spirometry and referred for further evaluation accordingly. The study identified 21 patients with airway obstruction out of 161 patients who were screened. A large-scale follow-up study that will assess cost and efficacy is ongoing. ${ }^{76}$ Additionally, in a manner similar to local outreach programs already in place (eg, to increase rates of recommended cancer screening), community hospitals may be well poised to serve as facilitators in initiating screening programs aimed at the early diagnosis of COPD.

\section{Large-scale public-health interventions}

Many countries have instituted large-scale efforts to promote awareness of COPD and encourage early diagnosis. These include the National Lung Health Education Program in the USA, as well as programs such as the Detection, Interaction and Monitoring of COPD and Asthma project in The Netherlands and the Know the Age of Your Lung project in Poland. ${ }^{77}$ The general goal of these programs is to perform spirometry in at-risk populations and identify patients at earlier stages of disease, thereby allowing intensive smoking-cessation counseling and potentially earlier treatment of patients with earlier-stage disease. Obviously, given the scope and heterogeneity of COPD in the world, initiating early intervention in those at-risk for progressive disease necessitates a large and multifaceted approach that requires the support of governments, medical societies, communities, and industry.

\section{Conclusion}

COPD is the most common chronic lung disease in the world, and while rates of cigarette smoking may be decreasing in many areas, it is evident that the future burden of this disease will be substantial throughout the world. Many patients with COPD go undiagnosed until late in their disease course, and, regardless of time of diagnosis, many patients continue to smoke until very advanced disease or death. The most rapid declines in lung function may occur in moderate disease, suggesting that diagnosing patients early on in their course may offer the best chance at mitigating the substantial morbidity and mortality associated with COPD. Early diagnosis is feasible and cost-effective in the primary-care setting, and efforts to expand diagnostic and therapeutic opportunities should be universally supported.

\section{Disclosure}

The authors declare no conflicts of interest in this work.

\section{References}

1. Vestbo J, Hurd SS, Agustí AG, et al. Global strategy for the diagnosis, management, and prevention of chronic obstructive pulmonary disease: GOLD executive summary. Am J Respir Crit Care Med. 2013;187(4): 347-365.

2. Anthonisen NR, Connett JE, Kiley JP, et al. Effects of smoking intervention and the use of an inhaled anticholinergic bronchodilator on the rate of decline of FEV1. The Lung Health Study. JAMA. 1994;272(19):1497-1505.

3. Decramer M, Cooper CB. Treatment of COPD: the sooner the better? Thorax. 2010;65(9):837-841.

4. Decramer M, Miravitlles M, Price D, et al. New horizons in early stage COPD - improving knowledge, detection and treatment. Respir Med. 2011;105(11):1576-1587.

5. Fletcher C, Peto R. The natural history of chronic airflow obstruction. Br Med J. 1977;1(6077):1645-1648.

6. Tantucci C, Modina D. Lung function decline in COPD. Int J Chron Obstruct Pulmon Dis. 2012;7:95-99.

7. Drummond MB, Hansel NN, Connett JE, Scanlon PD, Tashkin DP, Wise RA. Spirometric predictors of lung function decline and mortality in early chronic obstructive pulmonary disease. Am J Respir Crit Care Med. 2012;185(12):1301-1306.

8. Borrill ZL, Houghton CM, Tal-Singer R, et al. The use of plethysmography and oscillometry to compare long-acting bronchodilators in patients with COPD. Br J Clin Pharmacol. 2008;65(2):244-252.

9. Borrill ZL, Houghton CM, Woodcock AA, Vestbo J, Singh D. Measuring bronchodilation in COPD clinical trials. $\mathrm{Br} J$ Clin Pharmacol. 2005;59(4):379-384.

10. Frantz S, Nihlén U, Dencker M, Engström G, Löfdahl CG, Wollmer P. Impulse oscillometry may be of value in detecting early manifestations of COPD. Respir Med. 2012;106(8):1116-1123.

11. Oppenheimer BW, Goldring RM, Berger KI. Distal airway function assessed by oscillometry at varying respiratory rate: comparison with dynamic compliance. COPD. 2009;6(3):162-170. 
12. Mets OM, Schmidt M, Buckens CF, et al. Diagnosis of chronic obstructive pulmonary disease in lung cancer screening computed tomography scans: independent contribution of emphysema, air trapping and bronchial wall thickening. Respir Res. 2013;14:59.

13. Owrangi AM, Etemad-Rezai R, McCormack DG, Cunningham IA, Parraga G. Computed tomography density histogram analysis to evaluate pulmonary emphysema in ex-smokers. Acad Radiol. 2013;20(5): 537-545.

14. Johannessen A, Skorge TD, Bottai M, et al. Mortality by level of emphysema and airway wall thickness. Am J Respir Crit Care Med. 2013;187(6):602-608.

15. Decramer M, Celli B, Kesten S, Lystig T, Mehra S, Tashkin DP. UPLIFT investigators. Effect of tiotropium on outcomes in patients with moderate chronic obstructive pulmonary disease (UPLIFT) a prespecified subgroup analysis of a randomised controlled trial. Lancet. 2009;374(9696):1171-1178.

16. Jenkins CR, Jones PW, Calverley PM, et al. Efficacy of salmeterol/ fluticasone propionate by GOLD stage of chronic obstructive pulmonary disease: analysis from the randomised, placebo-controlled TORCH study. Respir Res. 2009;10:59.

17. Cukic V, Lovre V, Ustamujic A. The Changes of Pulmonary Function in COPD During Four-Year Period. Mater Sociomed. 2013;25(2):88-92.

18. Corsi DJ, Boyle MH, Lear SA, Chow CK, Teo KK, Subramanian SV. Trends in smoking in Canada from 1950 to 2011: progression of the tobacco epidemic according to socioeconomic status and geography. Cancer Causes Control. 2014;25(1):45-57.

19. Centers for Disease Control and Prevention. Cigarette smoking among adults - United States, 2007. MMWR Morb Mortal Wkly Rep. 2008;57(45):1221-1226.

20. Song Y, Zhao L, Palipudi KM, et al; the Global Adult Tobacco Survey (GATS) Collaborative Group. Tracking MPOWER in 14 countries: results from the Global Adult Tobacco Survey, 2008-2010. Glob Health Promot. Epub September 16, 2013.

21. Accordini S, Corsico AG, Cerveri I, et al. Diverging trends of chronic bronchitis and smoking habits between 1998 and 2010. Respir Res. 2013;14:16.

22. Nelson DE, Mowery P, Asman K, et al. Long-term trends in adolescent and young adult smoking in the United States: metapatterns and implications. Am J Public Health. 2008;98(5):905-915.

23. Ford ES, Croft JB, Mannino DM, Wheaton AG, Zhang X, Giles WH. COPD surveillance - United States, 1999-2011. Chest. 2013;144(1): 284-305

24. Ford ES, Mannino DM, Wheaton AG, Giles WH, Presley-Cantrell L, Croft JB. Trends in the prevalence of obstructive and restrictive lung function among adults in the United States: findings from the National Health and Nutrition Examination surveys from 1988-1994 to 2007-2010. Chest. 2013;143(5):1395-1406.

25. Mannino DM, Homa DM, Akinbami LJ, Ford ES, Redd SC. Chronic obstructive pulmonary disease surveillance - United States, 1971-2000. MMWR Surveill Summ. 2002;51(6):1-16.

26. Shahab L, Jarvis MJ, Britton J, West R. Prevalence, diagnosis and relation to tobacco dependence of chronic obstructive pulmonary disease in a nationally representative population sample. Thorax. 2006;61(12) 1043-1047.

27. Zhong N, Wang C, Yao W, et al. Prevalence of chronic obstructive pulmonary disease in China: a large, population-based survey. Am J Respir Crit Care Med. 2007;176(8):753-760.

28. Yin P, Zhang M, Li Y, Jiang Y, Zhao W. Prevalence of COPD and its association with socioeconomic status in China: findings from China Chronic Disease Risk Factor Surveillance 2007. BMC Public Health. 2011;11:586.

29. Lou P, Zhu Y, Chen P, et al. Vulnerability of patients with chronic obstructive pulmonary disease according to gender in China. Int $J$ Chron Obstruct Pulmon Dis. 2012;7:825-832.

30. Zeng G, Sun B, Zhong N. Non-smoking-related chronic obstructive pulmonary disease: a neglected entity? Respirology. 2012;17(6): 908-912.
31. Hu G, Zhou Y, Tian J, et al. Risk of COPD from exposure to biomass smoke: a metaanalysis. Chest. 2010;138(1):20-31.

32. Sood A, Petersen H, Blanchette CM, et al. Wood smoke exposure and gene promoter methylation are associated with increased risk for COPD in smokers. Am J Respir Crit Care Med. 2010;182(9):1098-1104.

33. Nishimura M, Makita H, Nagai K, et al; Hokkaido COPD Cohort Study Investigators. Annual change in pulmonary function and clinical phenotype in chronic obstructive pulmonary disease. Am J Respir Crit Care Med. 2012;185(1):44-52.

34. Tanabe N, Muro S, Tanaka S, et al. Emphysema distribution and annual changes in pulmonary function in male patients with chronic obstructive pulmonary disease. Respir Res. 2012;13:31.

35. Mohamed Hoesein FA, van Rikxoort E, van Ginneken B, et al. Computed tomography-quantified emphysema distribution is associated with lung function decline. Eur Respir J. 2012;40(4):844-850.

36. Agusti A, Calverley PM, Celli B, et al. Evaluation of COPD Longitudinally to Identify Predictive Surrogate Endpoints (ECLIPSE) investigators. Characterisation of COPD heterogeneity in the ECLIPSE cohort. Respir Res. 2010;11:122.

37. Couper D, Lavange LM, Han M, et al; for the SPIROMICS Research Group. Design of the Subpopulations and Intermediate Outcomes in COPD Study (SPIROMICS). Thorax. Epub September 12, 2013.

38. Regan EA, Hokanson JE, Murphy JR, et al. Genetic epidemiology of COPD (COPDGene) study design. COPD. 2010;7(1):32-43.

39. Rennard SI, Vestbo J, Agustí A. What is chronic obstructive pulmonary disease anyway?: Continua, categories, cut points, and moving beyond spirometry. Am J Respir Crit Care Med. 2013;187(10):1036-1037.

40. Enright PL, Ruppel GL. Don't use the flawed fixed ratio to diagnosis COPD. Respir Care. 2009;54(11):1500.

41. Mohamed Hoesein FA, Zanen P, Lammers JW. Lower limit of normal or FEV1/FVC $<0.70$ in diagnosing COPD: an evidence-based review. Respir Med. 2011;105(6):907-915.

42. Bhatt SP, Sieren JC, Dransfield MT, et al; for the COPDGene Investigators. Comparison of spirometric thresholds in diagnosing smokingrelated airflow obstruction. Thorax. Epub November 5, 2013.

43. Jögi J, Ekberg M, Jonson B, Bozovic G, Bajc M. Ventilation/perfusion SPECT in chronic obstructive pulmonary disease: an evaluation by reference to symptoms, spirometric lung function and emphysema, as assessed with HRCT. Eur J Nucl Med Mol Imaging. 2011;38(7):1344-1352.

44. National Cancer Institute. Biomarker. In: NCI Dictionary of Terms [website on the Internet]. Bethesda, MD: National Cancer Institute; nd. Available from: http://www.cancer.gov/dictionary?cdrid=45618. Accessed December 1, 2013.

45. Carolan BJ, Kim YI, Williams AA, et al. The association of adiponectin with computed tomography phenotypes in chronic obstructive pulmonary disease. Am J Respir Crit Care Med. 2013;188(5):561-566.

46. Cheng DT, Kim DK, Cockayne DA, et al; TESRA and ECLIPSE Investigators. Systemic soluble receptor for advanced glycation endproducts is a biomarker of emphysema and associated with AGER genetic variants in patients with chronic obstructive pulmonary disease. Am J Respir Crit Care Med. 2013;188(8):948-957.

47. Wang L, Tang Y, Liu S, et al. Metabonomic profiling of serum and urine by (1)H NMR-based spectroscopy discriminates patients with chronic obstructive pulmonary disease and healthy individuals. PLoS One. 2013;8(6):e65675.

48. Thomashow MA, Shimbo D, Parikh MA, et al. Endothelial microparticles in mild chronic obstructive pulmonary disease and emphysema. The Multi-Ethnic Study of Atherosclerosis Chronic Obstructive Pulmonary Disease study. Am J Respir Crit Care Med. 2013;188(1):60-68.

49. Kharitonov SA, Barnes PJ. Exhaled markers of pulmonary disease. Am $J$ Respir Crit Care Med. 2001;163(7):1693-1722.

50. Barnes PJ, Chowdhury B, Kharitonov SA, et al. Pulmonary biomarkers in chronic obstructive pulmonary disease. Am J Respir Crit Care Med. 2006;174(1):6-14.

51. Brindicci C, Ito K, Resta O, Pride NB, Barnes PJ, Kharitonov SA. Exhaled nitric oxide from lung periphery is increased in COPD. Eur Respir J. 2005;26(1):52-59. 
52. Borrill ZL, Roy K, Singh D. Exhaled breath condensate biomarkers in COPD. Eur Respir J. 2008;32(2):472-486.

53. Pelkonen $\mathrm{M}$, Tukiainen $\mathrm{H}$, Tervahauta $\mathrm{M}$, et al. Pulmonary function, smoking cessation and 30 year mortality in middle aged Finnish men. Thorax. 2000;55(9):746-750.

54. Chapman RS, He X, Blair AE, Lan Q. Improvement in household stoves and risk of chronic obstructive pulmonary disease in Xuanwei, China: retrospective cohort study. BMJ. 2005;331(7524): 1050 .

55. Edwards RD, Liu Y, He G, et al. Household CO and PM measured as part of a review of China's National Improved Stove Program. Indoor Air. 2007;17(3):189-203.

56. Freeman D, Lee A, Price D. Efficacy and safety of tiotropium in COPD patients in primary care - the SPiRiva Usual CarE (SPRUCE) study. Respir Res. 2007;8:45.

57. Dusser D, Bravo ML, Iacono P. The effect of tiotropium on exacerbations and airflow in patients with COPD. Eur Respir J. 2006; 27(3):547-555.

58. Boehringer Ingelheim Pharmaceuticals. Effects of tiotropium on breathing capacity and exercise limitation in early stages of chronic obstructive pulmonary disease. In: ClinicalTrials.gov [website on the Internet]. Bethseda, MD: US National Library of Medicine; 2010 [updated November 27, 2013]. Available from: http://clinicaltrial. gov/ct2/show/study/NCT01072396. NLM identifier: NCT01072396. Accessed December 2, 2013.

59. Tse HN, Raiteri L, Wong KY, et al. High-dose N-acetylcysteine in stable COPD: the 1-year, double-blind, randomized, placebo-controlled HIACE study. Chest. 2013;144(1):106-118.

60. Barnes PJ. Theophylline. Am J Respir Crit Care Med. 2013;188(8): 901-906.

61. Hospital Universitari Son Dureta. Effects of low-dose theophylline during chronic obstructive pulmonary disease (COPD) exacerbations. In: ClinicalTrials.gov [website on the Internet]. Bethseda, MD: US National Library of Medicine; 2008 [updated May 2, 2008]. Available from: http:/clinicaltrial.gov/ct2/show/NCT00671151. NLM identifier: NCT00671151. Accessed December 2, 2013.

62. Hospital Son Espases. Low-dose theophylline as anti-inflammatory enhancer in severe chronic obstructive pulmonary disease (ASSET). In: ClinicalTrials.gov [website on the Internet]. Bethseda, MD: US National Library of Medicine; 2012 [updated May 15, 2012]. Available from: http://clinicaltrial.gov/ct2/show/NCT01599871. NLM identifier: NCT01599871. Accessed December 2, 2013.

63. Assaf-Harofeh Medical Center. The effect on small airways of addition of theophylline as inducer of histone deacilase activity for patients with moderate to severe chronic obstructive pulmonary disease (COPD), treated with inhaled steroids and long acting beta agonists. In: ClinicalTrials.gov [website on the Internet]. Bethseda, MD: US National Library of Medicine; 2009 [updated April 4, 2011]. Available from: http://clinicaltrial.gov/ct2/show/NCT00893009. NLM identifier: NCT00893009. Accessed December 2, 2013.

64. Barnes PJ. New anti-inflammatory targets for chronic obstructive pulmonary disease. Nat Rev Drug Discov. 2013;12(7):543-559.
65. Weiss DJ, Casaburi R, Flannery R, LeRoux-Williams M, Tashkin DP. A placebo-controlled, randomized trial of mesenchymal stem cells in COPD. Chest. 2013;143(6):1590-1598.

66. Lacasse Y, Goldstein R, Lasserson TJ, Martin S. Pulmonary rehabilitation for chronic obstructive pulmonary disease. Cochrane Database Syst Rev. 2006;(4):CD003793.

67. Nici L, Donner C, Wouters E, et al; ATS/ERS Pulmonary Rehabilitation Writing Committee. American Thoracic Society/European Respiratory Society statement on pulmonary rehabilitation. Am J Respir Crit Care Med. 2006;173(12):1390-1413.

68. Puhan MA, Gimeno-Santos E, Scharplatz M, Troosters T, Walters EH, Steurer J. Pulmonary rehabilitation following exacerbations of chronic obstructive pulmonary disease. Cochrane Database Syst Rev. 2011;(10):CD005305.

69. Liu XL, Tan JY, Wang T, et al. Effectiveness of home-based pulmonary rehabilitation for patients with chronic obstructive pulmonary disease: a meta-analysis of randomized controlled trials. Rehabil Nurs. 2014;39(1):36-59.

70. Van Remoortel H, Hornikx M, Demeyer H, et al. Daily physical activity in subjects with newly diagnosed COPD. Thorax. 2013;68(10): 962-963.

71. Jácome CI, Marques AS. Pulmonary rehabilitation for mild chronic obstructive pulmonary disease: a 1 systematic review. Respir Care. Epub October 8, 2013.

72. National Lung Screening Trial Research Team, Aberle DR, Adams AM, et al. Reduced lung-cancer mortality with low-dose computed tomographic screening. N Engl J Med. 2011;365(5):395-409.

73. Dirven JA, Tange HJ, Muris JW, van Haaren KM, Vink G, van Schayck OC. Early detection of COPD in general practice: patient or practice managed? A randomised controlled trial of two strategies in different socioeconomic environments. Prim Care Respir J. 2013;22(3):331-337.

74. Dirven JA, Tange HJ, Muris JW, van Haaren KM, Vink G, van Schayck OC. Early detection of COPD in general practice: implementation, workload and socioeconomic status. A mixed methods observational study. Prim Care Respir J. 2013;22(3):338-343.

75. Castillo D, Guayta R, Giner J, et al; FARMAEPOC group. COPD case finding by spirometry in high-risk customers of urban community pharmacies: a pilot study. Respir Med. 2009;103(6):839-845.

76. Collegide Farmacèutics de la Província de Barcelona. Chronic obstructive pulmonary disease case finding in community-pharmacies by spirometry (FARMAEPOC). In: ClinicalTrials.gov [website on the Internet]. Bethseda, MD: US National Library of Medicine; 2012 [updated April 11, 2012]. Available from: http://clinicaltrial.gov/ ct2/show/NCT01576068. NLM identifier: NCT01576068. Accessed December 2, 2013.

77. Price D, Freeman D, Cleland J, Kaplan A, Cerasoli F. Earlier diagnosis and earlier treatment of COPD in primary care. Prim Care Respir J. 2011;20(1):15-22.
International Journal of COPD

\section{Publish your work in this journal}

The International Journal of COPD is an international, peer-reviewed journal of therapeutics and pharmacology focusing on concise rapid reporting of clinical studies and reviews in COPD. Special focus is given to the pathophysiological processes underlying the disease, intervention programs, patient focused education, and self management protocols.
Dovepress

This journal is indexed on PubMed Central, MedLine and CAS. The manuscript management system is completely online and includes a very quick and fair peer-review system, which is all easy to use. Visit $\mathrm{http}: / / \mathrm{www}$. dovepress.com/testimonials.php to read real quotes from published authors. 